\title{
Highly Selective Purification of Grewia asiatica Anthocyanin Based on Macroporous Resins
}

\author{
Marvi Kanwal Talpur ${ }^{1 *}$, Farah Naz Talpur ${ }^{1}$, Aamna Balouch ${ }^{1}$, Shafi M. Nizamani ${ }^{1}$, \\ Muhammad Ali Surhio ${ }^{1}$, Muhammad Raza Shah ${ }^{2}$, Muhammad Iqbal Bhanger ${ }^{2}$, \\ Hassan Imran Afridi ${ }^{1}$ and Shagufta Qambrani ${ }^{1}$ \\ ${ }^{1}$ National Centre of Excellence in Analytical Chemistry, University of Sindh, Jamshoro, 76080, Pakistan. \\ ${ }^{2}$ H.E.J. Research Institute of Chemistry, International Centre for Chemical and Biological Sciences, \\ University of Karachi, Karachi 75270, Pakistan. \\ *Corresponding Author Email: kanwaltalpur@hotmail.com \\ Received 02 November 2020, Revised 15 May 2021, Accepted 19 May 2021
}

\begin{abstract}
In the present study, enactments and separation characteristics of five extensively utilized adsorbents for enhancement and purification of Grewia asiatica Anthocyanins (ACNs) extracts were analysed. Among five tested resins (AB-8, Sepabeads Sp-700, C18SPE Cartridge, Sepabeads Sp-207 and AB-80), AB-8 resin exhibited the best adsorbent ability for Grewia asiatica ACNs $(84.24 \mathrm{mg} / \mathrm{mL}$ resin). Results of static adsorption tests revealed that AB-8 resin selected for kinetics and isotherm experiments followed a pseudo 2nd order model along with Langmuir isotherm. In order to improve operational procedure, dynamic adsorption and desorption tests were done on a packed column of AB-8 resin. Optimum factors for subsequent adsorption-desorption experiments; processing volume $20 \mathrm{ml}$, flow rate $2 \mathrm{~mL} / \mathrm{min}$ with elution solvent of acidified methanol $(1 \% \mathrm{v} / \mathrm{v})$ were used. HPLC and LC-MS/MS profiles of the purified extract confirmed seven ACNs in Grewia asiatica samples, out of which cyanidin-3-O-(6"acetylglucoside) comprises 44-63\% (695 $\mu \mathrm{g} / \mathrm{g})$ of total ACNs composition. Moreover, pigment purification using AB-8 resin did not alter ACNs mixture composition after purification but enhance the peak intensity and gives effective purification. Hence present work reveals that the separation procedure established through column chromatography providing an effective methodology to enhance the purification of ACNs from Grewia asiatica.
\end{abstract}

Keywords: Anthocyanins, Grewia asiatica, cyanidin-3-O-(6"acetylglucoside), AB-8resin, LCMS/MS analysis.

\section{Introduction}

Anthocyanin's (ACNs) belongs to the flavonoid's family, gives red, blue, and purple colours to fruits and vegetables [1]. Farther the colorant belongings, ACNs have shown antioxidant abilities with anti-inflammatory, anticancer, and antimicrobial activities, in addition to reducing eyestrain and protecting DNA damage, etc. [2,3]. In addition, ACNs, as natural pigments, have accepted the rising importance to use them as food colorants.
Therefore, there is a growing interest in the use of anthocyanins as food colourants and dietary antioxidant supplements in the current time $[4,5]$.

Grewia asiatica L., genus (Tiliaceae), commonly called phalsa, is a good flavoured significant marketable fruit widely produced in Pakistan and is also cultivated in south Asian countries [6]. Grewia asiatica fruit is 
rich in vitamins, minerals as well as high fibre with low calories. Grewia asiatica fruit is useful for heart, blood, liver, anorexia and gastritis disorders [6,7]. Grewia asiatica contains phenolics, flavonoids and antioxidants (vitamin C, tannins, ACNs) [8]. Anthocyanin's are largely extracted from plants by solid-liquid extraction method using various acidified solvents [9]. In our previous study, we have determined ACNs in Grewia asiatica using acidic methanol as $1193.8 \mu \mathrm{g} / \mathrm{g}$ on a fresh weight basis; the major ACNs detected were cyaniding - 3 - O - (6"acetylglucoside) and peonidin-3-O-glucoside [10]. The result indicated that ACNs were more stable at 10$40{ }^{\circ} \mathrm{C}$ in the dark as compared to luminescent light.

However, crude extract of ACN have impurities, carbohydrates and phenolics, which reduced the biological activities and stability of ACNs. When extracted from various fruits like Red Raspberry [11, 12]. Separation of ACNs carried out by liquidliquid extraction or preparative highperformance liquid chromatography (HPLC) [1]. It is inefficient and costly to promote [13]. Column chromatography is getting popular now a days for purification of ACNs, it gives large quantities of fractions for successive identification as well as isolation of pure substances. Normally used column adsorbents are RP-C18 [12], Toyopearl, macroporous adsorption resin [14] and Sephadex LH-20 [15]. The separation of ACNs from plant crude extracts using macroporous resins is an efficient process due to their exceptional adsorption properties (greater adsorption and at easy desorption capacities). Moreover, this technique has benefits, like a low price, simple and great efficiency [16].

No previous studies have been found to purify ACNs from Grewia asiatica. Our study aims to progress a modest and efficient technique for primary enhancement of ACNs from Grewia asiatica extracts. The resins used in the study have diverse polarities such as AB-8, Sepabeads Sp-700, C18SPE Cartridge, Sepabeads Sp-207 and AB-80. ACNs adsorption/desorption properties were also evaluated along with the use of popular isotherm models (Langmuir and Freundlich) to envisage the resin performance. Lastly, ACNs of Grewia asiatica, purified through column chromatography, were separated and identified by HPLC-ESI-MS.

\section{Materials and Methods \\ Chemicals and Reagents}

Analytical grade acetic acid, acetonitrile, hydrochloric acid, ethanol, ethyl acetate and methanol were obtained from FischeScientific Ltd. (Loughborough, UK) and Sigma Aldrich (Darmstadt, Germany). Standard of ACNs such as 3-O- $\alpha$-glucosides chloride of cyanidin (cy), pelargonidin (pg), delphinidin (dp), peonidin (pn), petunidin (pt), malvidin (mv) as well as cyanidin-3-O-rutinoside (keracyanin Chloride) with a purity of $99 \%$ were purchased from Applicam (Darmstadt, Germany). Five macroporous resins / adsorbents containing AB-8, Sepabeads Sp-700, C18SPE Cartridge, Sepabeads Sp-207 and AB-80 were purchased by Shangai Hualing Resin co. Ltd. and Sigma Aldrich (Darmstadt, Germany).

\section{Collection of Samples and Extract Preparation}

Ripe (purplish coloured and semicircular single-seeded) fruit samples of Grewia asiatica L., genus (Tiliaceae) were obtained from indigenous Hyderabad markets province Sindh, Pakistan. Anthocyanin's were extracted by following our previously described method [10]. 


\section{Adsorption Capacity of Selected Resins}

Before use, pre-selected resins were saturated for one day in ethanol. The adsorption capacity of macro porous resins were analysed by static adsorption test using procedure as follows; five $50 \mathrm{~mL}$ erlemenry flasks containing pre-weighed amount $5 \mathrm{~mL}$ of each resin (equal to $0.25 \mathrm{~g}$ dry resin) with starting concentration of $1193(\mathrm{mg} / \mathrm{L})$. In all flasks, $20 \mathrm{~mL}$ of extracted sample were added sealed tightly with a cap while $\mathrm{pH}$ of the solution was adjusted at 3.0. After that, all samples were placed in an incubator shaker at $100 \mathrm{rpm}$ for one day at $25^{\circ} \mathrm{C}$ temperature. Concentrations of ACNs in resulting solutions were analysed by UV-Visible spectrophotometer and their adsorption capability summarized in (Table 1).

Adsorption capacity (qe) of all selected resins $(\mathrm{mg} / \mathrm{g})$ was determined using following formula:

$$
\mathrm{qe}=\frac{\mathrm{C}_{\mathrm{o}}-\mathrm{C}_{\mathrm{e}}}{\mathrm{w}} \times v
$$

Where qe showing adsorption capacity $(\mathrm{mg} / \mathrm{g}) ; \mathrm{C}_{\mathrm{o}}$ and $\mathrm{C}_{\mathrm{e}}(\mathrm{mg} / \mathrm{mL})$ are initial and equilibrium concentration; $\mathrm{W}$ is the weight of dry resin $(\mathrm{g})$ while $\mathrm{V}(\mathrm{mL})$ is sample solutions volume.

Table 1. Characteristics of the Adsorbent resins used and their adsorption properties on phalsa (Grewia asiatica) fruit Anthocyanin's.

\begin{tabular}{cccccc}
\hline $\begin{array}{c}\text { Resin } \\
\text { series }\end{array}$ & Matrix & $\begin{array}{c}\text { Specific } \\
\text { surface } \\
\text { area } \\
\left(\mathbf{m}^{2} / \mathbf{g}\right)\end{array}$ & $\begin{array}{c}\text { Pore } \\
\text { size } \\
(\mathbf{n m})\end{array}$ & $\begin{array}{c}\text { Chemical } \\
\text { Nature }\end{array}$ & $\begin{array}{c}\text { Adsorption } \\
\text { capacity, } \\
\mathbf{q e}(\mathbf{m g} / \mathbf{g})\end{array}$ \\
\hline AB-8 & $\begin{array}{c}\text { Cross-linked } \\
\text { polystyrene }\end{array}$ & $\begin{array}{l}480-520 \\
13-14\end{array}$ & $\begin{array}{c}\text { Weak } \\
\text { polar }\end{array}$ & 84.24 \\
$\begin{array}{c}\text { Sepabeads } \\
\text { Sp 700 }\end{array}$ & $\begin{array}{c}\text { Polydivinyl } \\
\text { benzene }\end{array}$ & 1100 & 9 & $\begin{array}{c}\text { Non- } \\
\text { polar }\end{array}$ & 77.84 \\
$\begin{array}{c}\text { C18SPE } \\
\text { Cartridge }\end{array}$ & Silica & 500 & 6 & $\begin{array}{c}\text { Non- } \\
\text { Polar }\end{array}$ & 70.80 \\
$\begin{array}{c}\text { Sepabeads } \\
\text { Sp 207 }\end{array}$ & $\begin{array}{c}\text { Brominated } \\
\text { styrene- }\end{array}$ & 650 & 10.5 & $\begin{array}{c}\text { Strongly } \\
\text { Polar }\end{array}$ & 65.28 \\
$\begin{array}{c}\text { AB-80 } \\
\text { resin }\end{array}$ & Sulfonic acid & $480-520$ & $13-14$ & $\begin{array}{c}\text { Strongly } \\
\text { Polar }\end{array}$ & 55.52 \\
\hline
\end{tabular}

\section{Static Adsorption Isotherms}

Adsorption isotherms on AB-8 resin with higher adsorption capacity $(84.24 \mathrm{mg} / \mathrm{mL})$ were analysed by the same process as defined in above section with varying initial concentrations 1193, 1073, 953, 833, 713 and $593 \mathrm{mg} / \mathrm{mL}$ for ACNs.

Two popular theoretical models Langmuir and Freundlich were used to define adsorption performance among adsorbent and adsorbed material. The following equation was used for Langmuir model:

$$
\frac{\mathrm{C}_{\mathrm{e}}}{\mathrm{C}_{\mathrm{ads}}}=\frac{1}{\mathrm{Q}_{\mathrm{b}}}+\frac{\mathrm{C}_{\mathrm{e}}}{\mathrm{Q}}
$$

Where $\mathrm{C}_{\mathrm{ads}}(\mathrm{mg} / \mathrm{g})$, is the quantity of Grewia asiatica ACNs adsorbed on AB-8 resin surface. Ce denotes equilibrium concentration $(\mathrm{mg} / \mathrm{g}), \quad \mathrm{Q} \quad(\mathrm{mg} / \mathrm{g})$ represents adsorption capacity and $\mathrm{b}$ is Langmuir constant in $\mathrm{L} / \mathrm{mg}$. value of $\mathrm{Q}$ and Langmuir isotherm constants of the adsorbent were calculated by intercept as well as the slope of linear plot log Ce/Qe against Ce (Fig. 1). The Langmuir adsorption isotherm equation might be declared in the expression of dimensionless constant named an equilibrium factor or separation factor ' $R L$ ' expressed using subsequent equation:

$\mathrm{RL}=\frac{1}{1}+\mathrm{bC}_{\mathrm{o}}$

Here RL is the separation factor; $b$ is similar as described above, whereas Co is the initial concentration $(\mathrm{mg} / \mathrm{g})$ of Grewia asiatica ACNs. Using separation factor RL can be calculated if $\mathrm{RL}>1$; isotherm unfavourable, for linear isotherm $\mathrm{RL}=1$; isotherm is favourable if $0<R L<1$; and for irreversible isotherm $\mathrm{RL}=0$

Freundlich equation is

$\mathrm{q}_{\mathrm{e}}=\frac{\mathrm{Kf}}{\left(\mathrm{C}_{\mathrm{e}}\right)} 1 / \mathrm{n}$ 
Where $\mathrm{q}_{\mathrm{e}}$ and $\mathrm{C}_{\mathrm{e}}$ are similar as defined above, $\mathrm{Kf}(\mathrm{mg} / \mathrm{g})$ and $1 / \mathrm{n}$ are Freundlich and empirical constant. The linked parameters were calculated by obtained intercept and slope values of linear plot (Table 2) presented in results and discussion section.

\section{Static Adsorption and Desorption Kinetics}

Anthocyanin's adsorption and desorption study for selected AB-8 was done conferring to the process defined above. ACNs amount in Grewia asiatica extract was checked at equal time intermissions until adsorption equilibrium achieved. Once static adsorption equilibrium achieved, AB-8 resin was eroded with $1 \% \mathrm{v} / \mathrm{v}$ acidified methanol $(\mathrm{pH}=2)$ and taken into $50 \mathrm{~mL}$ Erlenmeyer flask. After that, flasks were placed in a shaker (100 rpm) for $24 \mathrm{~h}$ at $28{ }^{\circ} \mathrm{C}$. Desorbed anthocyanins were analysed by UV-Visible spectrophotometer at various intervals in the desorption solution.

Desorption parameters were calculated using the below equation:

$\mathrm{D}=\frac{\mathrm{C}_{\mathrm{d}} \mathrm{V}_{\mathrm{d}}}{\mathrm{C}_{\mathrm{o}}-\mathrm{C}_{\mathrm{e}} \times \mathrm{V}} \times 100 \%$

D represents desorption ratio; $\mathrm{Cd}$ $(\mathrm{mg} / \mathrm{mL})$ is the amount of the solute, $\mathrm{Vd}(\mathrm{mL})$ is desorption volume. Where $\mathrm{C}_{\mathrm{o}}, \mathrm{C}_{\mathrm{e}}$, and $\mathrm{V}$ are same parameters as discussed above.

Adsorption kinetics gives evidence about the rate of the adsorption process, practical applicability and information about the mechanism of the diffusion of the solute at the adsorbent surface. In this context the kinetics of adsorption was studied using Lagergren's pseudo-1st order and HoMcKay's pseudo-2nd order model [17].

Parameters of adsorption kinetics were calculated with pseudo-1st order and pseudo2 nd order rate equations given below:
$\operatorname{In}\left(\mathrm{q}_{1}(\mathrm{e}-) \mathrm{q}_{\downarrow} \mathrm{t}\right)=\operatorname{Inq}_{\mathrm{e}}-\frac{\mathrm{k}_{1 \mathrm{t}}}{2.303}$

Where $\mathrm{q}^{\mathrm{t}}$ and $\mathrm{q}^{\mathrm{e}}(\mathrm{mg} / \mathrm{g})$ signifies adsorbed amount of ACNs at equilibrium time correspondingly, $\mathrm{k} 1\left(\mathrm{~min}^{-1}\right)$ is the rate constant of pseudo-1st order

$$
\frac{1}{\mathrm{qt}}=\frac{1}{\mathrm{k}_{2} \mathrm{q}_{\mathrm{e}}^{2}}+\frac{\mathrm{t}}{\mathrm{q}_{\mathrm{e}}}
$$

$\mathrm{b}=\mathrm{kq}_{\mathrm{e}}^{2}$

Where $\mathrm{k}_{2}(\mathrm{~g} / \mathrm{mg}$. min) is rate constant of pseudo-2nd order. t/qt versus t plotted for pseudo-2nd order model shown in Fig. 2 gives an acceptable correlation coefficient, however; $\mathrm{k}$, and qe determined from value of intercept and slope.

\section{Dynamic Adsorption and Desorption Tests}

Dynamic adsorption and desorption experiments were accompanied in glass column of $15 \mathrm{~cm}$ in length and $300 \mathrm{~mm}$ in diameter containing $5 \mathrm{ml}$ of $\mathrm{AB} 8$ resin equal to $0.25 \mathrm{~g}$ dry weight. Bed volume (BV) of resin was $20 \mathrm{~mL}$. The sample solution was introduced into the column through a peristaltic pump (ZT60-600) Baoding Lange Constant Pump Co., Ltd., Hebei, China at approved $2 \mathrm{~mL} / \mathrm{min}$ flow rate and temperature was maintained at $25^{\circ} \mathrm{C} .10 \mathrm{~mL}$ fractions of sample solution was collected and ACNs concentration in the removal solution was analysed with the help of UV-VIS spectrophotometer. After adsorption equipoise at elevated condition, column loaded with $\mathrm{AB}$ 8 resin was consecutively eluted with acidified methanol containing $1 \% \mathrm{v} / \mathrm{v} \mathrm{HCl}$ at flow rate of $2 \mathrm{~mL} / \mathrm{min}$. Saturation capability and breakthrough curve were determined based on the quantity of ACNs adsorbed.

\section{HPLC-Analysis and Characterization of Anthocyanin's}

Hypersil gold C18 analytical column $(250 \times 4.6 \mathrm{~mm}, 5 \mu \mathrm{m})$ of Thermo scientific 
modal fitted with a $30 \mathrm{~mm} \times 2.1 \mathrm{~mm}$ guard column and diode array detection was performed at $520 \mathrm{~nm}$ using auto sampler UV 6000LP series HPLC (Thermo electronic corporation). Formic acid solution $(5 \% \mathrm{v} / \mathrm{v})$ with methanol at the ratio of 15: 85 were used as a mobile phase and the flow rate was set at $1 \mathrm{~mL} \mathrm{~min}{ }^{-1}$ (Wu \& Prior, 205).

Structure elucidation was done by injecting $10-\mu \mathrm{l}$ of purified ACNs solution to an Agilent triple quadruple liquid chromatograph-mass spectrometer (model 6460) furnished with electro-spray ionization (ESI) interface with positive ionization mode. MS operating settings were as monitors: nebulizer gas pressure was set at 45 psi while flow rate maintained at $12 \mathrm{~mL}$ $\mathrm{min}^{-1}$. The whole scan was accomplished in 350 to $1500 \mathrm{~m} / \mathrm{z}$ with capillary voltage $3500 \mathrm{~V}$ [18].

\section{Results and Discussion Adsorption Behaviour of Selected Resin}

Adsorption performances of resins used for anthocyanin's are shown in Table 1. AB-8 showed higher adsorption abilities to ACNs as compare to other resin. Adsorption capability of resin is associated with chemical features of the solute and the resins [19]. The weak-polar AB-8 resin exhibited the greatest adsorption ability $(84.24 \mathrm{mg} / \mathrm{g})$, because it has a high surface area with a similar polarity index towards weak-polar ACNs, moreover, AB-8 resin had a greater pore diameter as compared to other reported resins [20] such as LS-305A LS610B for the purification of Anthocyanin's from the Calyx Extract of Roselle (Hibiscus sabdariffa L.). Hence AB-8 resin showed improved adsorption capacities for Grewa asiatica ACNs, and hence the reason to use AB-8 resin for kinetics tests (adsorption and desorption).

\section{AB-8 resin Adsorption Isotherms}

AB-8 resin Equilibrium isotherms at $25{ }^{\circ} \mathrm{C}$ for ACNs purification was studied. Langmuir and Freundlich calculations deal with linearity fitting of data as well as that define how adsorbate relates to resins. Generally, Langmuir model tells us about monomolecular layer distribution of adsorption energies over a homogeneous surface without being interacted with adsorbed molecules [21]. Freundlich equation gives an idea about the behaviour of adsorption (physical or chemical). It also defines adsorption performance of mono molecular layer or multi-molecular layer. Isotherms of Langmuir and Freundlich were plotted and presented in Fig. 1 (a \& b).
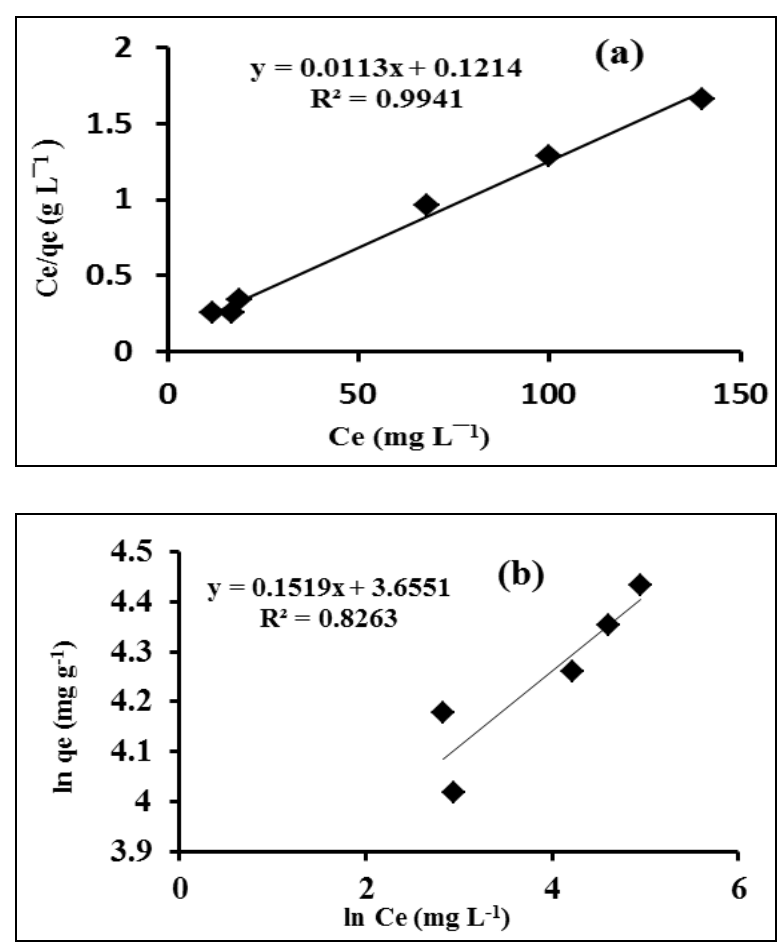

Figure 1. Langmuir (a) and freundlich (b) plot for anthocyanin's adsorption on AB-8 resin.

Result parameters based on these isotherms are summarized in Table 2, with the initial concentration of $1193 \mathrm{mg} / \mathrm{mL}$. As shown in Table 2, correlation coefficients obtained from Langmuir was higher $>0.994$ 
than Freundlich equations $<0.826$ specifies the adsorption process was a monolayer. From the Freundlich equation (Eq.4), the value of $n$ was 6.58, which lies between 1-10, indicating the adsorption can take feasibly. Moreover, the RL value from Langmuir isotherm also ranges between 0 to 1 , which signifies that the adsorption is favourable to the conditions being applied. Hence, AB-8 resin was suitable for ACNs purification; these results were consistent with the earlier observation for the purification of ACNs for Red Raspberry using macro porous resin [22].

Table 2. Anthocyanin's adsorption: Langmuir and Freundlich isotherm constants.

\begin{tabular}{|c|c|c|c|c|c|c|}
\hline \multicolumn{4}{|c|}{ Langmiur } & \multicolumn{3}{|c|}{ Freundlich } \\
\hline $\begin{array}{c}Q \\
\left(m g g^{-1}\right)\end{array}$ & $\begin{array}{c}b \\
\left(\mathrm{Lmg}^{-1}\right)\end{array}$ & $R L$ & $R^{2}$ & $\begin{array}{c}K f \\
\left(m g g^{-1}\right)\end{array}$ & $n$ & $R^{2}$ \\
\hline 88.495 & 0.0930 & $\begin{array}{c}0.008- \\
0.017\end{array}$ & 0.9941 & 1.2961 & 6.5832 & 0.8263 \\
\hline
\end{tabular}

The Langmuir adsorption capacities compared with other reported literature are shown in Table 3.

Table 3. Comparison of adsorption capacity of AB-8 resin for Grewia asiatica Anthocyanin with other reported adsorbents.

\begin{tabular}{ccc}
\hline Adsorbents & $\begin{array}{c}\text { Adsorption } \\
\text { capacity (mg/g) }\end{array}$ & References \\
\hline DM-130 & 26.72 & {$[13]$} \\
LS-610B & 31.95 & {$[14]$} \\
LS-305 & 38.16 & {$[23]$} \\
AB-8 & 84.24 & Present study \\
\hline
\end{tabular}

\section{Adsorption and Desorption Kinetics on AB-8 Resin}

Kinetics defines the speed and time of adsorption from the start to the equilibrium. For adsorption, kinetic studies of ACNs of Grewia asiatica pseudo-1st-order and 2nd order models were applied. Pseudo-1st-order model normally valid for first phase of adsorption procedure while, 2nd order kinetic model predicts the nature of adsorption (chemical or physical). The adsorption kinetics of anthocyanin's displayed in table 4 and Fig. 2 (a,b), the R2 values (0.9652) observed with the pseudo-first-order kinetic model were lower than for the pseudo-secondorder kinetic models (0.9978). The pseudosecond-model calculated value (Qe 33333.33) is also close to the experimental data (Qe 32953.48). Outcomes indicated that pseudo 2nd order model gave a better explanation of ACNs adsorption on AB-8 resin. Similar observations were obtained by Kang et al., [24].

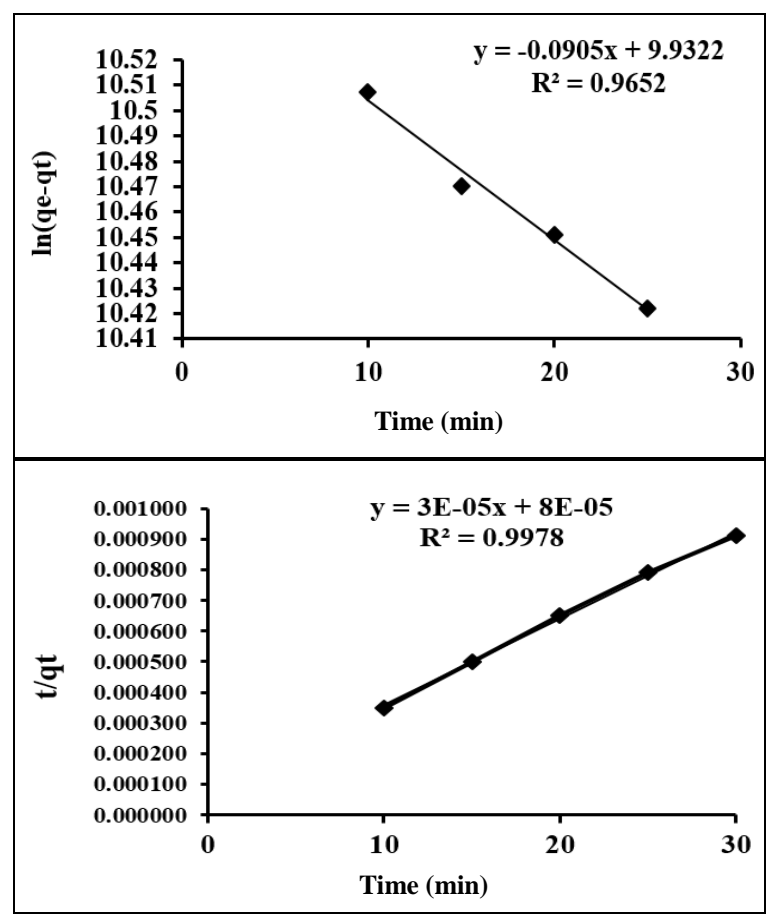

Figure 2. Kinetic model plots of pseudo 1st order (a) and pseudo 2nd order (b) for the anthocyanin's adsorption on AB-8 resin.

Table 4. Kinetic model parameters for the Adsorption of Anthocyanin's by Grewia Asiatica (Phalsa) fruit.

\begin{tabular}{|c|c|c|c|c|c|}
\hline \multicolumn{2}{|c|}{ Pseudo-first order } & \multicolumn{3}{|c|}{ Pseudo-second order } & $\begin{array}{l}\text { Experi- } \\
\text { mental }\end{array}$ \\
\hline $\begin{array}{c}k_{1} \\
\left(\min ^{-1}\right)\end{array}$ & $\begin{array}{c}q_{e}, \text { cal } \\
(\mathrm{mg} / \mathrm{g})\end{array}$ & $\begin{array}{c}K_{2} \\
(\text { g/mg.min })\end{array}$ & $\begin{array}{c}q_{e}, c a l \\
(m g / g)\end{array}$ & $R^{2}$ & $\begin{array}{c}q, \exp \\
(\mathrm{mg} / \mathrm{g})\end{array}$ \\
\hline
\end{tabular}

$\begin{array}{lllllll}0.20842 & 2.2957 & 0.9652 & 0.00001125 & 33333.33 & 0.9978 & 32953.48\end{array}$ 
Dynamic Adsorption and Desorption Curve on AB-8 Resin

Factors like loading volume and flow rate of solute as well as eluent are important in order to analyse dynamic adsorption and desorption of Grewia asiatica ACNs. Experiments were done to calculate breakthrough point at which ACNs concentration keeps increasing in fraction. Dynamic break through curve of AB- 8 resin depend upon volume of eluent and the amount of solute enters into column. As Fig. 3 (a) revealed that once the collective volume of eluent reached up to $20 \mathrm{~mL}$ anthocyanin's of Grewia asiatica were fully adsorbed on the surface of AB-8 resin, beyond this quantity the concentration of anthocyanin's increases until it reaches at adsorption (break-through point). The flow rate of AB-8 resin is set at $2 \mathrm{~mL} / \mathrm{min}$, whereas in subsequent dynamic adsorption experiments, $20 \mathrm{~mL}$ of the sample solution was used.

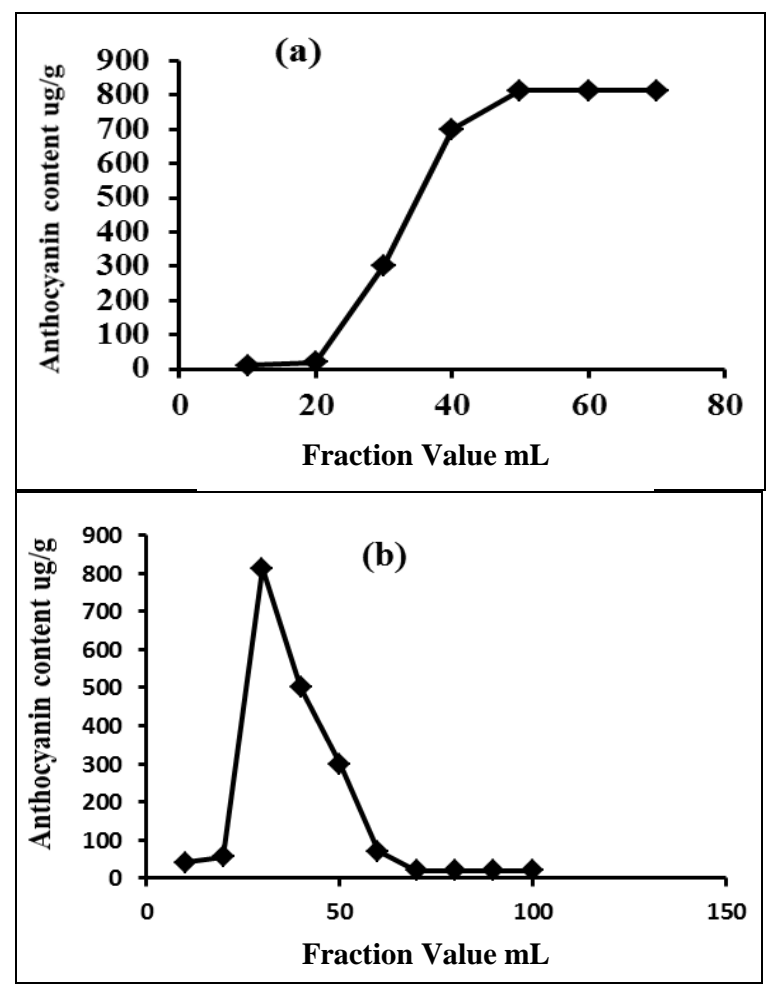

Figure 3. Dynamic breakthrough curves of Grewia asiatica extract anthocyanins (a) adsorption and (b) desorption on AB-8 resin
Dynamic desorption curve for $\mathrm{AB}-8$ resin was drawn for eluent anthocyanin concentration vs. elution volume at $2 \mathrm{~mL} / \mathrm{min}$ flow rate as shown in (Fig. 3b). The complete desorption of anthocyanin was achieved at 70 $\mathrm{ml}$ with acidified methanol $(1 \% \mathrm{v} / \mathrm{v})$, in the beginning with initial $20 \mathrm{~mL}$ of solvent, only $2.04 \%$ of anthocyanin were eluted, but as the elution volume increases and reaches up to 60 $\mathrm{mL}$ an enhancement in anthocyanin's concentration occurs $(98.96 \%)$. Hence the conditions for the purification of Grewia asiatica anthocyanin's on $\mathrm{AB}-8$ resin; $20 \mathrm{~mL}$ loading volume with $70 \mathrm{~mL}$ of elution volume utilizing acidified methanol $(1 \% \mathrm{v} / \mathrm{v})$ as the desorption agent were used.

\section{HPLC Analysis of Purified Anthocyanin's}

The HPLC analysis revealed seven anthocyanin's in Grewia asiatica in consent with our previous study [10]. Crude Grewia asiatica extract is rich in ACNs contains and can be exploited as a regular colorant. Though, crude extract of ACNs contain impurities like carbohydrates, ore and proteins in bulk quantities. Contrary to crude anthocyanin's extract, the extract purified with AB-8 resin removes maximum impurities. Elimination of impurities from ACNs not only enhances its stability as promising food pigment but also reduces reactions (enzymatic and non-enzymatic) leads changing of colour. The purified extract, when analysed through HPLC at identical wavelength $(520 \mathrm{~nm})$, HPLC chromatogram was same for purified as well as crude extracts, comprising seven peaks as presented in Fig 4 ( $a$ and $b)$. It indicates that purification of $\mathrm{ACNs}$ using $\mathrm{AB}$ 8 resin did not alter its configuration but enhance the peak intensity and gives effective purification. Also, LC-MS-MS confirmed seven Anthocyanin's in Grewia asiatica samples with non-acylated, acylated and pyranoanthocyanin such as (delphinidin-3-O-glucoside, peonidin-3-O- 
glucoside, pelargonidin-3- O-malonyl glucoside), (cyanidin-, peonidin-, and pelargonidin-3-O-6"-acetylglucoside) (Malvidin-3-O-glucoside pyruvic acid). Amongst all cyanidin-3-O-(6"acetylglucoside) containing $44-63 \%(695 \mu \mathrm{g} / \mathrm{g})$ of ACNs composition followed by peonidin-3-O-glucoside comprising $3-30 \% \quad(163.6 \mu \mathrm{g} / \mathrm{g})$ and pelargonidin-3-O-(6"-acetyl glucoside) $8-14 \%$ (140.4 $\mu \mathrm{g} / \mathrm{g})$.
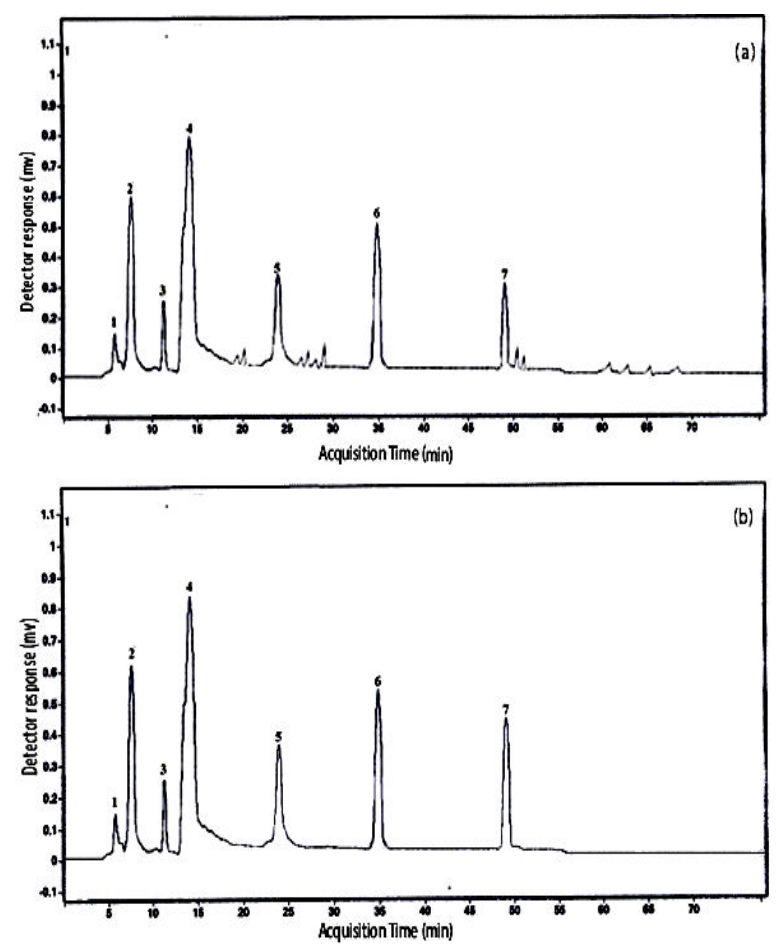

Figure 4. HPLC chromatogram of Grewia asiatica extract anthocyanins (a) before purification and (b) after purification on AB-8 resin

\section{Conclusion}

In the present work, separation features of five type of macroporous resins were methodically examined. AB-8 resin demonstrated the best adsorbent capability for Grewia asiatica ACNs $(84.24 \mathrm{mg} / \mathrm{mL}$ resin) because of its large surface area as compared to other adsorbents. Static tests outcomes revealed that experimental data close-fitted to pseudo-2nd order model along with Langmuir isotherm model gave good correlation coefficients (0.9941). Dynamic adsorption and desorption tests were performed on a column packed with AB-8 resin. The acidified methanol solution with $1 \% \mathrm{v} / \mathrm{v} \mathrm{HCl}$ was determined as the appropriate desorption solution with a processing volume of $20 \mathrm{~mL}$ and $2 \mathrm{~mL} / \mathrm{min}$ flow rate. This method could be utilized in large-scale production of anthocyanin purification from Grewia asiatica or other plant extracts in industry due to the prominent advantages of the macroporous resin method, including procedural simplicity, lower cost, lower labor intensity, higher purification efficiency, and easier scale-up.

\section{Conflict of Interest}

The authors declare that there is no conflict of interest.

\section{Reference}

1. R. Byamukama, B. T. Kiremire, Ø. M. Andersen and A. Steigen, J. Food Compos. Anal., 599 (2005) 18. doi.org/10.3390/antiox 8080299

2. L. Jakobek and M. Seruga, Int. J. Food Prop., $122 \quad$ (2012) 15 https://doi.org/10.1080/10942911003754684

3. J. He and M. Monica Giusti, Annu. Rev. Food Sci. Technol., 163 (2010) 1. 10.1146/annurev.food.080708.100754

4. A. Kassim, J. Poette, A. Paterson, D. Zait, S. McCallum, M. Woodhead, K. Smith, C. Hackett and J. Graham, Mol. Nutr. Food Res., 22 (2009) 5. doi 10.1002/mnfr.200800174

5. L. Verbeyst, K. Van Crombruggen, I. Van der Plancken and M. Hendrickx, A. Van Loey, J. Food Eng., 513 (2011) 3. doi:10.1016/j.jfoodeng.2011.03.015

6. M. Zia-Ul-Haq, M. S. Stanković, K. Rizwan and V. De Feo, Molecules, 2663 (2013) 18.

doi:10.3390/molecules18032663

7. R. K. Mishra, S. P. Patel, A. Srivastava, R. K. Vashistha, A. Singh and A. K. Puskar, Nat. Sci., 22 (2012) 10. 
https://www.researchgate.net/publication /285736749_Ethnomedicinally_importan t_plants_of_Pachmarhi_region_Madhya Pradesh_India

8. M. N. Asghar, I. U. Khan, L. Sherin and M. Ashfaq, Asian J. Chem., 5123 (2008) 20.

asianjournalofchemistry.co.in/User/Sear

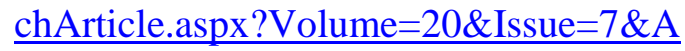
rticle $=\&$ Criteria $=$

9. Z. Huang, B. Wang, P. Williams and R. D. Pace, Asian J. Chem., 12 (2009) 42. doi.org/10.1016/j.lwt.2008.11.005

10. M. Talpur, F. Talpur, A. Balouch, S. Nizamani and M. Surhio, MOJ Food Process. Technol., 299 (2017) 5. doi: 10.15406/mojfpt.2017.05.00127

11. J. Dai and R. J. Mumper, Molecules, 7313 (2010) 15.

doi:10.3390/molecules15107313

12. C. S. Bowen-Forbes, Y. Zhang and M. G. Nair, J. Food Compos. Anal., 554 (2010) 23. doi.org/10.1016/j.jfca.2009.08.012

13. S.-Q. Cao, S .-Y. Pan, X.-L. Yao and H.F. Fu, Agr. Sci. China, 207 (2010) 9. doi.org/10.1016/S1671-2927(09)60085-7

14. X.-L. Chang, D. Wang, B.-Y. Chen, Y.M. Feng, S.-H. Wen and P.-Y. Zhan, $J$. Agric. Food Chem., 2368 (2012) 60. doi.org/10.1021/jf205311v

15. Y. Zhang, X. Liao, F. Chen, J. Wu and X. Hu, Eur. Food Res. Technol., 1445 (2008) 226.

doi.org/10.1007/s00217-006-0550-3
16. W. Liu, S. Zhang, Y.-G. Zu, Y.-J. Fu, W. Ma, D.-Y. Zhang, Y. Kong and X.-J. Li, Bioresour. Technol., 4667 (2010) 101.

doi.org/10.1016/j.biortech.2010.01.058

17. F. Amin, F. N. Talpur, A. Balouch, Z. A. Chandio, M. A. Surhio and H. I. Afridi, Environ. Prog. Sustain. Energy, 1274 (2016) 35. doi 10.1002/ep.12342

18. F. Chen, Y. Sun, G. Zhao, X. Liao, X. $\mathrm{Hu}, \mathrm{J} . \mathrm{Wu}$ and $\mathrm{Z}$. Wang, Ultrason. Sonochem., 767 (2007) 14. doi.org/10.1016/j.ultsonch.2006.12.011

19. Y. Lu, C. Zhang, P. Bucheli and D. Wei, Plant Foods Hum. Nutr., 55 (2006) 61. doi: 10.1007/s11130-006-0014-8

20. X.-Y. Sun, Q.-Z. Tuo, Z.-Y. Liuyang, A.-J. Xie, X.-L. Feng, X. Yan, M. Qiu, S. Li, X.-L. Wang and F.-Y. Cao, Cell Death Dis., 2449 (2016) 7. doi:10.1038/cddis.2016.329

21. M. Amara and H. Kerdjoudj, Talanta, 21 (2003) 60. doi:10.1016/S0039-9140(03)00155-3

22. Y. Yang, X. Yuan, Y. Xu and Z. Yu, Int. J. Food Prop., 1046 (2015) 18. doi.org/10.1080/10942912.2013.862632

23. C. Lv, J. Yang, R. Liu, Q. Lu, Y. Ding, J. Zhang and J. Deng, Food Chem. 183 (2018) 268. doi.org/10.1016/j.foodchem.2018.06.100

24. Y. J. Kang, S. W. Jung, and S. J. Lee, Food Sci. Biotechnol., 23 (2014) 97. https://dio.org/101007/s10068-014-0013-8 